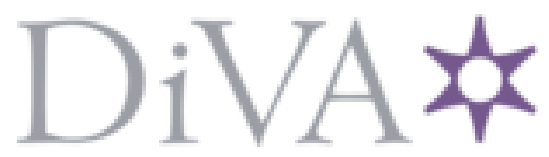

http://www.diva-portal.org

This is the published version of a paper published in Vård $i$ Norden.

Citation for the original published paper (version of record):

Fridlund, B., Baigi, A., Hildingh, C. (2010)

Developing and testing the psychometric properties of a short-form questionnaire regarding the psychosocial condition after a cardiac event.

Vård i Norden, 30(2): 29-32

Access to the published version may require subscription.

N.B. When citing this work, cite the original published paper.

Permanent link to this version:

http://urn.kb.se/resolve?urn=urn:nbn:se:hh:diva-4755 


\title{
Developing and testing the psychometric properties of a short-form questionnaire regarding the psychosocial condition after a cardiac event
}

\author{
Bengt Fridlund, RNT PhD Professor FESC - Amir Baigi, MSc (stat) PhD Associate Professor - Cathrine Hildingh, RNT PhD \\ Professor FESC
}

\section{ABSTRACT}

Psychosocial difficulties in patients after a cardiac event is well-known concept yet no systematic or routine assessment with focus on their psychosocial condition with regard to coping, social support and sense of coherence is established. Accordingly the aim of this pilot study was to develop and test the psychometric properties of a short-form questionnaire regarding patients' psychosocial condition after a cardiac event to be used in every day clinical practice. This pilot study, which had a methodological design, used selected sample of 30 participants to answer a questionnaire built on 37 items in order to determine face, content and construct validity and homogeneity reliability. Five factors built on 18 items emerged, all with good values for the psychometric tests chosen, and labelled according to their theoretical belongings: closeness, belongingness, availability, concordance and outlook. This short-form questionnaire measuring the psychosocial condition after a cardiac event useful in every day clinical practice seems appropriate but needs further psychometric development carried out in large scale studies with regard to cultural-socio-demographics and diagnoses.

KEY WORDS: coronary heart disease, coping, methodology, psychometric, social support, validity

\section{Introduction}

A cardiac event puts life on a knife's edge and the consequence is to cope with a new life including a different lifestyle carried out by patients themselves and with social support from healthcare professionals in order to achieve a sense of coherence in the renewable life (1-3). As the recovery initiates already in the hospital and runs lifelong healthcare professionals both inside (4) and outside (5) the hospital have to take care of and interplay with the patients $(6,7)$ in order to support their own efforts and possibilities to improve and maintain a healthy lifestyle. Psychosocial difficulties in patients after a cardiac event are well-known among the healthcare professionals (8) yet no systematic or routine assessment with focus on their psychosocial condition with regard to coping, social support and sense of coherence is established (9). A good reason for this is that no convenient instrument exists even though several instruments exist with regard to both generic and condition-specific measurements of coping (e.g. 10-16), social support (e.g. 17-20) and sense of coherence (e.g. 21-23). In case of a shortform questionnaire, both easy to carry out and easy to assess the patient's principal psychosocial condition and ability at hospital discharge $(4,24)$ or at follow-ups in the primary health care $(25,26)$ more individualized care could be offered and the health and medical service could be more appropriately utilized with regard to both appropriate care and effective economical management (27). Accordingly the aim of this pilot study was to develop and test the psychometric properties of a short-form questionnaire concerning patients' psychosocial condition after a cardiac event with reference to coping, social support and sense of coherence to be used in every day clinical practice.

\section{Method and material}

\section{Design and setting}

This pilot study had a methodological design (28) and was carried out during 2007 with permission of and at The Heart and Lung Patients' National Association (HLPNA) in Sweden. HLPNA is a non-profit organization working for the goal of quality of life for people with heart and lung disease (29).
Participants and data collection

An eligible and selected sample of 30 participants (67\% men and 33\% women) with an average age of 69.1 (SD 11.57) was recruited from HLPNA's newspaper Status and is why participants representing all counties of Sweden were represented. The inclusion criteria for the participants were their own experiences of cardiac disease and that they could communicate verbally and textually.

The Psychosocial Condition Questionnaire

The questionnaire for assessing psychosocial condition comprised initially 37 items based on a literature review regarding sense of coherence, coping and social support and from clinical and theoretical experiences as cardiovascular nurses and researchers $(\mathrm{BF}, \mathrm{CH})$. The answers were scored on a 5-point Likert scale, measuring level of agreement from "strongly agree" to "do not agree at all".

\section{Validity and reliability process and analysis}

The research team which comprised, besides the two nurses also a statistician $(\mathrm{AB})$ well-established in the cardiovascular field examined the questionnaire regarding its readability, face and content validity (30). For the same reason the questionnaire was piloted on three cardiac nurses and three former cardiac patients with minor corrections as a consequence. Construct validity was measured by an explorative factor analysis: i.e. a principal component analysis with varimax rotation to simplify the factor structure for best fit with communalities $>0.5$ was looked for $(30,31)$. To explain a total variance $>60 \%$ orthogonal factors with an Eigenvalue $>1.0$ emerging for each factor were searched (31). Likewise for each factor, items with factor loadings $>0.5$ was looked for. Homogeneity measured by Cronbach's coefficient alpha was searched for to reach reliability scores $>0.7$ (31). The data processing and analysis was carried out using SPSS for Windows 15.0 .

\section{Ethics}

The study, conducted according the to the rules of the Helsinki Declaration on informed consent and confidentiality, was approved by the HLPNA board in Sweden. The participants were informed about the 
Table 1. Validity and reliability tests of the conclusive 18-item Psychosocial Condition Questionnaire calculated by means of factor analysis and Cronbach's alpha, $n=30$

\begin{tabular}{|c|c|c|c|c|c|c|c|c|c|}
\hline & $\begin{array}{l}\text { Mean } \\
\text { (SD) }\end{array}$ & $\begin{array}{l}\text { Communality } \\
\text { Extraction }\end{array}$ & $\begin{array}{l}\text { Eigen } \\
\text { Values }\end{array}$ & $\begin{array}{l}\text { Cumulative } \\
\text { Variance \% }\end{array}$ & F1 & F2 & F3 & F4 & F5 \\
\hline \multicolumn{10}{|c|}{ Closeness } \\
\hline I1 & $8.5(2.0)$ & 0.90 & & & 0.91 & & & & \\
\hline $\mathrm{I} 2$ & $8.2(2.0)$ & 0.92 & & & 0.89 & & & & \\
\hline $\mathrm{I} 3$ & $8.3(2.0)$ & 0.84 & & & 0.86 & & & & \\
\hline \multirow[t]{2}{*}{ I4 } & $8.8(1.3)$ & 0.86 & & & 0.85 & & & & \\
\hline & & & 7.3 & 40.6 & & & & & \\
\hline Alpha & & & & & $(0.94)$ & & & & \\
\hline \multicolumn{10}{|c|}{ Belongingness } \\
\hline I5 & $7.5(2.7)$ & 0.91 & & & & 0.89 & & & \\
\hline I6 & $7.7(2.2)$ & 0.87 & & & & 0.81 & & & \\
\hline I7 & $6.2(2.8)$ & 0.75 & & & & 0.79 & & & \\
\hline I8 & $6.9(2.8)$ & 0.78 & & & & 0.69 & & & \\
\hline I9 & $7.7(2.2)$ & 0.70 & & & & 0.65 & & & \\
\hline \multirow[t]{2}{*}{ I10 } & $7.1(2.7)$ & 0.69 & & & & 0.56 & & & \\
\hline & & & 2.4 & 54.1 & & & & & \\
\hline Alpha & & & & & & $(0.88)$ & & & \\
\hline \multicolumn{10}{|c|}{ Availability } \\
\hline I11 & $7.5(2.6)$ & 0.89 & & & & & 0.92 & & \\
\hline $\mathrm{I} 12$ & $7.4(2.5)$ & 0.84 & & & & & 0.90 & & \\
\hline \multirow[t]{2}{*}{ I13 } & $7.9(1.5)$ & 0.65 & & & & & 0.50 & & \\
\hline & & & 2.0 & 65.2 & & & & & \\
\hline Alpha & & & & & & & $(0.77)$ & & \\
\hline \multicolumn{10}{|c|}{ Concordance } \\
\hline I14 & $6.0(2.1)$ & 0.76 & & & & & & 0.85 & \\
\hline \multirow[t]{2}{*}{ I15 } & $6.6(2.4)$ & 0.84 & & & & & & 0.84 & \\
\hline & & & 1.4 & 73.2 & & & & & \\
\hline Alpha & & & & & & & & $(0.73)$ & \\
\hline \multicolumn{10}{|c|}{ Outlook } \\
\hline I16 & $6.9(2.8)$ & 0.72 & & & & & & & 0.66 \\
\hline I17 & $6.1(1.6)$ & 0.74 & & & & & & & 0.55 \\
\hline \multirow[t]{2}{*}{ I18 } & $6.9(2.5)$ & 0.55 & & & & & & & 0.52 \\
\hline & & & 1.0 & 78.8 & & & & & \\
\hline Alpha & & & & & & & & & $(0.63)$ \\
\hline
\end{tabular}

Kaiser-Meyer-Olkin Measure of Sampling Adequacy (KMO): Bartlett's test of Sphericity: $p<.001$

Factor 1: Closeness; Factor 2: Belongingness; Factor 3: Availability; Factor 4: Concordance; Factor 5: Outlook. Overall Cronbach's alpha: 0.89.

aim and the structure of the study, after which they gave their informed consent. Participation was voluntarily and the participants were informed that they could withdraw from the study at any time.

\section{Results}

The face and content validity was found to be good as the respondents understood the text in the questionnaire and considered the items to be relevant for the focus of measure as well as having clarity and readability. According to skew dispersion and low communalities 19 items were deleted, which is why the factor analysis resulted in the extraction of five factors with an Eigenvalue $>1.0$ accounting for $78.8 \%$ of total variance based on 18 items (Figure 1). Each factor contained between two and six items all reaching factor loadings $>0.5$. All items together showed a Cronbach's alpha value of 0.89 and with any item deleted a range of 0.88-0.90. Each factor was labeled according to their theoretical belongings, and all but one displayed a Cronbach's alpha value $>0.7$, allocated on 0.94 for the 4-item factor 1 labeled Closeness, 0.88 for the 6-item factor 2 labeled Belongingness, 0.77 for the 3-item factor 3 labeled Availability, 0.73 for the 2-item factor 4 labeled Concordance, and 0.63 for the 3 -item factor 5 labeled Outlook.

\section{Discussion}

A short-form questionnaire easy to hand out at hospital discharge or at follow-up in primary health care was developed and tested in a pilot and methodological study. By using common psychometric tests good validity and reliability figures were found with regard to content and construct validity and homogeneity reliability (31). However the questionnaire needs to be further developed according to concurrent validity and stability reliability but it needs also to be tested in large scale studies as a whole comprising differences in patients' cultural-sociodemographics and cardiac diagnoses. Nevertheless the questionnaire has a solid and careful foundation based on a literature review regarding social support, coping and sense of coherence as well as on clinical and theoretical experiences of the researchers. The five factors which emerged and were labeled according to their theoretical belongings are all well rooted in the psychosocial area of cardiac care (8). Moreover internal as well as external resources are of importance to manage the consequences of a strain situation, like a cardiac event $(22,23,32)$. It is of great importance to healthcare professionals in their work with cardiac patients to have knowledge about how patients perceive their own resources to cope with the new situation to be able to facilitate the recovery process $(2,9)$. The short-form questionnaire illuminates what kind of support that is available and also beliefs of internal resources to cope with the situation. Social support has emotional as well as more practical dimensions $(19,33)$. The factor Closeness deals with emotional support and shows that the individual perceives themselves to have access to persons with whom they can share joy and sorrow, persons who give them time, care about them and show them that they are valued as they are (17). This kind of resources can create a feeling of meaningfulness in life of importance to the individual's ability to manage strain situations (32). Also Belongingness deals with emotional aspects of social support. Belongingness to a social network leads to a feeling of sense of community and social integration. When support network members give valuable and sincere response to the individual to issues related to him or herself information leads to the belief that one is cared for and loved, esteemed and a member of a network of 
Figure 1.The 18 items in its entirety which conclusively became part of the Psycho-Social Condition Questionnaire after having been tested for validity and reliability

I1: I have people in my vicinity that I can share joys and sorrows with

I2: I have people in my vicinity that gives the time with me

I3: I have people in my vicinity, which shows that I will do as I am

I4: I have people in my vicinity who care about how I have it

I5: I have the opportunity to carry me to the members of my social network

I6: I have people in my social network that gives me practical help when I need

I7: I can carry out almost anything that I made up my mind for

I8: I meet people who are part of my social networks often

I9: I have people in my social network that I can borrow the little things when I need such as tools or cookware

I10: I live in the vicinity of the members of my social network

I11: The people included in my social networks know each other

I12: The people included in my social networks know each other through me

I13: I have people in my vicinity that gives me a sincere response to issues relating to me

I14: The people included in my social network has the same lifestyle that I have

I15: I have members of my social network that gives me good advice

I16: What happens to me in the future depends largely on myself

I17: The people included in my social network has the same values as I have

I18: I have people in my social network that keeps me informed about important matters in my surroundings

mutual obligations (34). This in turn can influence the individual's ability to manage the situation after a cardiac event. The factor Concordance deals with harmonious and mutual understanding - of good and evil. If network members have the same lifestyle, they can give useful and helpful advice to each other. This in turn may contribute to feelings of comprehensibility, another component of Antonovsky's theory of sense of coherence (32). However, the advices may not always contribute to a positive outcome, e.g. adoption of a healthy lifestyle, even if the advice is experienced as supportive by the individual. Another factor is Availability dealing with resources like transportation, practical help, living nearby network members (17) as well as inner resources like beliefs that one can carry out almost anything one set's one's mind to. This inner resource helps the individual to cope with strain situations and is in accordance with manageability, the third component of Antonovsky's theory (32), a belief that one has the skills or ability, the support and the resources necessary to take care of things, and that things are manageable within one's own control (32). Here the individual use coping strategies like fighting spirit, self-control and confrontation. The last factor, Outlook also involve perceptions of inner resources and perspectives of existence, and deals with one's own responsibility for what happens in the future, but also questions the values of network members and to be informed about important matters in the surroundings. To some degree this factor is overlapping with the factor Belongingness but belongingness has a more emotional aspect as the response deals with the individual, while the latter deals with matters in the surroundings. The factor Outlook had a somewhat low factor loading in the factor analysis performed, but is anyway an important factor on its own. Healthcare professionals can support patients to cope with the cardiac event if they are aware of what kind of resources, internal as well as external, their patients have. A short-form questionnaire of what kind of support is available as well as patients' own beliefs of internal resources to cope with the new situation may be a good help in healthcare professionals attempts.

\section{Conclusion}

A short-form questionnaire regarding patients' psychosocial condition after a cardiac event to be used in every day clinical practice was developed and tested in a pilot study. Good validity and reliability figures were found with regard to content and construct validity as well as homogeneity reliability. There is a need for further psychometric development of the questionnaire and tests in large scale studies with regard to cultural-socio-demographics and diagnoses.

\section{Accepted for publication 16.03.2010}

Fridlund B, RNT PhD Professor FESC (1), Baigi A, MSc (stat) PhD Associate Professor (2), Hildingh C, RNT PhD Professor FESC (3)

(1) School of Health Sciences, Jönköping University, Jönköping, Sweden

(2) Primary Health Care R\&D Unit, County Council Halland, Falkenberg, Sweden

(3) School of Social and Health Sciences, Halmstad University, Halmstad, Sweden

Correspondence: Prof Bengt Fridlund, School of Health Sciences, Jönköping University, POBox 1026, 55111 SE - Jönköping, Sweden bengt.fridlund@hhj.hj.se

\section{References}

1. Baigi A, Hildingh C, Virdhall H, Fridlund B. Sense of coherence as well as social support and network as perceived by patients with a suspect or manifest myocardial infarction: a short time follow-up study. Clinical Rehabilitation 2008;22(7):646-52

2. Gulliksson M, Burell G, Lundin L et al. Psychosocial factors during the first year after a coronary heart disease event in cases and referents. Secondary Prevention in Uppsala Health Care Project (SUPRIM). BMC Cardiovascular Disorder 2007;21(7):36

3. Shen BJ, Wachowiak PS, Brooks LG. Psychosocial factors and assessment in cardiac rehabilitation. Europa Medicophysica 2005;41(1):75-91

4. Wiess ME, Piacentine LB. Psychometric properties of the Readiness for Hospital Discharge Scale. Journal of Nursing Measurement 2006;14(3): 163-80

5. Alm-Roijer C, Fridlund B, Stagmo M, Erhardt L. Knowing your risk factors for coronary heart disease improves adherence to advice on lifestyle changes and medication. Journal of Cardiovascular Nursing 2006;21(5): E24-31)

6. Wood DA, Kotseva K, Connolly S, et al. Nurse-coordinated multi-disciplinary, family-based cardiovascular disease prevention programme (EUROACTION) for patients with coronary heart disease and asymptomatic individuals at high risk of cardiovascular disease: a paired cluster-randomised controlled trial. Lancet 2008;37(9629):1999-2012

7. Westin L, Nilstun T. Principles help to analyse but often give no solution secondary prevention after a cardiac event. Health Care Analysis 2006; 14(2):111-17

8. Rozanski A, Blumenthal JA, Davidson KW et al. The epidemiology, pathophysiology, and management of psychosocial risk factors in cardiac practice: the emerging field of behavioral cardiology. Journal of American College of Cardiology 2005:1;45(5):637-51

9. Hildingh C, Fridlund B, Baigi A. Sense of coherence and experiences of social support and mastery in the early discharge period after an acute cardiac event. Journal of Clinical Nursing 2008;17(10):1303-11

10. Cooper C, Katona C, Livingstone G. Validity and reliability of the brief COPE in careers of people with dementia: the LASER-AD Study. Journal of Neurological Mental Disease 2008;196(11):838-43

11. Addison CC, Campell-Jenkins BW, Sarpong DF. Psychometric evaluation of coping strategies inventory short-form (CSI-SF) in the Jackson Heart Study cohort. International Journal of Environmental Research and Public Health 2007;4(4):289-95

12. Erci B. Psychometric evaluation of Self-Assessed Support Need of Women with breast cancer Scale. Journal of Clinical Nursing 2007;16(10):1927-35 
13. Ryan-Wenger NM. Development and psychometric properties of the Schoolagers' Coping Strategies Inventory. Nursing Research 1990;39(6): 344-49

14. Scheier MF, Carver CS. Optimism, coping and health: assessment and implications generalized outcome expectancies. Health Psychology 1985; 4(3):219-47

15. Jalowiec A, Murphy SP, Powers MJ. Psychometric assessment of the Jalowiec Coping scale. Nursing Research 1984;33(3):157-61

16. Pearlin LI, Schooler C. The structure of coping. Journal of Health and Social Behavior 1978;19(1):2-21

17. Hildingh C, Fridlund B. Patient participation in peer support groups after a cardiac event. British Journal of Nursing 2001;10(20):1357-63

18. Heitman L. Social support and cardiovascular health promotion in families. Journal of Cardiovascular Nursing 2004;19(1):86-91

19. Cohen S, Mermelstein R, Kamarek K, et al. Measuring the functional components of social support. In: Sarason IG, Sarason BR (Eds). Social support: Theory research and applications. Dodrecht: Martinus Nijholt, 1985: 73-94

20. Henderson S, Ducan-Jones P, Byrne DG, Scott R. Measuring social relationship: the interview schedule for social interaction. Psychological Medicine 1980;10:723-34

21. Antonovsky A. The life cycle, mental health and the sense of coherence. Israel Journal of Psychiatry and Related Sciences 1985;22:273-80

22. Eriksson M, Lindström B. Antonovsky's sense of coherence scale and its relation with quality of life. A systematic review. Journal of Epidemiological and Community Health 2007;61(11):938-44

23. Eriksson M, Lindström B. Antonovsky's sense of coherence scale and its relation with health. A systematic review. Journal of Epidemiological and Community Health 2006;60(5):376-81

24. Sjöström-Strand A, Fridlund B. Stress in women's daily life before and after a first myocardial infarction: a qualitative study. Scandinavian Journal of Caring Sciences 2007;21(1):10-7

25. Murchie P, Campell NC, Ritchie LD, Thain J. Running nurse-led secondary prevention clinics for coronary heart disease in primary care: qualitative study of health professionals' perspectives. British Journal of General Practice 2005;55(516):522-18

26. Stewart DE, Abbey SE, Shnek ZM et al. Gender differences in health information needs and decisional preferences in patients recovering from an acute ischemic coronary event. Psychosomatic Medicine 2004;66(1):42-48

27. Jolly K, Taylor R, Lip GY et al. The Birmingham Rehabilitation Uptake Maximisation study (BRUM) Home-based compared with hospital-based cardiac rehabilitation in a multi-ethnic population: cost-effectiveness and patient adherence. Health and Technology Assessment 2007;11(35):1-118

28. Brink PJ, Wood MJ. Advanced design in nursing research. London: SAGE, 1998:413

29. Hildingh C, Fridlund B. A 3-year follow-up participation in peer support groups after a cardiac event. European Journal of Cardiovascular Nursing 2004;3(4):315-20

30. Polit DF, Beck CT. Nursing research: generating and assessing evidence for nursing practice. Philadelphia: Wolters Kluwer Health/Lippincott Williams \& Wilkins, 2008:xviii,796

31. Rattray J, Jones MC. Essential elements of questionnaire design and development. Journal of Clinical Nursing 2007;16:234-43

32. Antonovsky A. Unraveling the Mystery of Health: How people manage stress and stay well. San Francisco: Jossey-Bass, 1987

33. House JS. Work, stress and social support. Philippines: Addison-Wesley Publishing Company. 1981:13-40

34. Cobb S. Social support as a moderator of life stress. Psychosomatic Medicine 1976;38(5):300-314 